\title{
Effects of resocialization on post-weaning social isolation- induced abnormal aggression and social deficits in rats
}

\begin{tabular}{|c|c|}
\hline Journal: & Developmental Psychobiology \\
\hline Manuscript ID: & DEV-12-075.R1 \\
\hline Wiley - Manuscript type: & Research Article \\
\hline Date Submitted by the Author: & 25-Sep-2012 \\
\hline Complete List of Authors: & $\begin{array}{l}\text { Tulogdi, Áron; Institute of Experimental Medicine, Department of } \\
\text { Behavioural Neuroscience } \\
\text { Tóth, Máté; Institute of Experimental Medicine, Department of Behavioural } \\
\text { Neuroscience } \\
\text { Barsvári, Beáta; Institute of Experimental Medicine, Department of } \\
\text { Behavioural Neuroscience } \\
\text { Biró, László; Institute of Experimental Medicine, Department of Behavioural } \\
\text { Neuroscience } \\
\text { Mikics, Éva; Institute of Experimental Medicine, Department of Behavioural } \\
\text { Neuroscience } \\
\text { Haller, József; Institute of Experimental Medicine, Department of } \\
\text { Behavioural Neuroscience }\end{array}$ \\
\hline Keywords: & $\begin{array}{l}\text { Post-weaning social isolation, Abnormal aggression, Social deficits, } \\
\text { Resocialization, Rats }\end{array}$ \\
\hline
\end{tabular}




\title{
Title page
}

Title: Effects of resocialization on post-weaning social isolation-induced abnormal aggression and social deficits in rats

Short title: Resocialization of aggressive isolated rats with social deficits

Authors: Áron Tulogdi, Máté Tóth, Beáta Barsvári, László Biró, Éva Mikics, József Haller

Affiliation: Institute of Experimental Medicine, Department of Behavioral Neuroscience, Budapest, Hungary

E-mail addresses: ÁT: tulogdi.aron@koki.mta.hu; MT: toth.mate@koki.mta.hu;

BB: barsvari.beata@koki.mta.hu; LB: biro.laszlo@koki.mta.hu; ÉM: mikics.eva@koki.mta.hu; JH: haller.jozsef@koki.mta.hu

\author{
Corresponding author: \\ Áron Tulogdi \\ Institute of Experimental Medicine \\ Department of Behavioral Neuroscience \\ H-1450 Budapest \\ P.O. Box 67 \\ Hungary \\ E-mail: tulogdi.aron@koki.mta.hu \\ Phone:+3612109408 \\ Fax: +36 12109951
}


As previously shown, rats isolated from weaning develop abnormal social and aggressive behavior characterized by biting attacks targeting vulnerable body parts of opponents, reduced attack signaling and increased defensive behavior despite increased attack counts. Here we studied whether this form of violent aggression could be reversed by resocialization in adulthood. During the first weak of resocialization, isolation-reared rats showed multiple social deficits including increased defensiveness and decreased huddling during sleep. Deficits were markedly attenuated in the second and third weeks. Despite improved social functioning in groups, isolated rats readily showed abnormal features of aggression in a resident-intruder test performed after the three week-long resocialization. Thus, post-weaning social isolation-induced deficits in prosocial behavior were eliminated by resocialization during adulthood, but abnormal aggression was resilient to this treatment. Findings are compared to those obtained in humans who suffered early social maltreatment, and who also show social deficits and dysfunctional aggression in adulthood.

Key words: early social deprivation, defensive aggression, huddling, social avoidance, withdrawal, resocialization 
Adverse childhood environment, e.g. early social neglect and maltreatment was suggested to be a risk factor for multiple psychiatric problems later in life (Acarturk et al., 2009; Johnson, Cohen, Brown, Smailes, \& Bernstein, 1999; Johnson, Smailes, Cohen, Brown, \& Bernstein, 2000; Krischer \& Sevecke, 2008; Spinhoven et al., 2010; Widom, Czaja, \& Paris, 2009). Emotional and behavioral consequences are anxiety, social withdrawal and hyper-arousal (Gunnar, Morison, Chisholm, \& Schuder, 2001; Hildyard \& Wolfe, 2002; Queiroz et al., 1991; Shaffer, Yates, \& Egeland, 2009). It was shown that these adverse early conditions contribute to excessive aggressive behavior in adolescence and adulthood (Krischer \& Sevecke, 2008; Maxfield \& Widom, 1996; McCord, 1983; Rivera \& Widom, 1990; Widom, 1989). There are reports about possible pharmacological treatments for these symptoms, as well as about psychotherapy or cognitive behavior therapy, however, treatment efficacy is unsatisfactory (Canton, Scott, \& Glue, 2012; Currie \& Startup, 2012; Goedhard et al., 2006; McCloskey, Noblett, Deffenbacher, Gollan, \& Coccaro, 2008; Turgay, 2004; B. Weiss et al., 2005; Willutzki, Teismann, \& Schulte, 2012).

From a translational perspective, it is fundamental to develop valid models of childhood maltreatment (Veenema, 2009) to test the potential efficacy of these pharmacological and behavioral interventions. Post-weaning social isolation of rats and other species leads to a wide range of social and nonsocial disabilities, including heightened aggression, disturbed social behavior and lack of proper social skills (Fone \& Porkess, 2008; Harlow, Dodsworth, \& Harlow, 1965; Potegal \& Einon, 1989; Von Frijtag, Schot, van den Bos, \& Spruijt, 2002; Wiberg \& Grice, 1963; Wongwitdecha \& Marsden, 1996). We have shown earlier that post-weaning social isolation of rats leads to hyperarousal-driven abnormal aggression in adulthood. Isolation-reared rats show a considerable increase in the share of attack bites that are aimed at vulnerable body 
parts of opponents (head, throat, belly), (Tóth, Halász, Mikics, Barsy, \& Haller, 2008; Toth, Mikics, Tulogdi, Aliczki, \& Haller, 2011; Toth et al., 2012). This pattern of aggression is associated with autonomic and glucocorticoid hyperreactivity (Toth, et al., 2011). Isolationreared rats show ambiguous aggressive behavior, as their enhanced aggression is also accompanied by increased defensive behavior and by decreased attack signaling (offensive behavior) which is not present in socially reared groups. This indicates that post-weaning social isolation induces a marked social disturbance associated with heightened arousal states. It is important to note that autonomic and glucocorticoid reactivity following post-weaning social isolation was not consistent across studies, as enhanced, unaltered or even decreased functions were reported in response to various nonsocial stimuli (Gentsch, Lichtsteiner, \& Feer, 1981; Sánchez, Aguado, Sánchez-Toscano, \& Saphier, 1998; Schrijver, Bahr, Weiss, \& Würbel, 2002; I. C. Weiss, Pryce, Jongen-Rêlo, Nanz-Bahr, \& Feldon, 2004). However, social challenges following post-weaning social isolation consistently showed autonomic and glucocorticoid hyper-reactivity (Toth, et al., 2011; van den Berg et al., 1999).

In the present study we addressed whether resocialization in adulthood, a laboratory analogue of behavioral therapy, can ameliorate social disturbances resulting from post-weaning social isolation. Huddling during sleep was measured in the inactive phase (daylight) of the day along a three week-long resocialization period in adulthood. We analyzed this behavior, because it is a general feature of social species including rats and may be used as an indicator of social cohesion (Alberts, 2007; Batchelder, Kinney, Demlow, \& Lynch, 1983; Takahashi, 1997). Aggressive behavior of isolated rats was also analyzed quantitatively and qualitatively in two different contexts: in the resident-intruder test before and after three weeks of resocialization in adulthood, and in the social context of this resocialization period. 


\section{Methods \\ Animals}

Male Wistar rats (Charles-River) from the breeding facility of our Institute were used in the present study. Pups were weaned on the 21st postnatal day and were either housed individually, or in groups of 4 rats for 7 weeks in Makrolon cages measuring 42 x 26 x $19 \mathrm{~cm}$. When group-housed animals reached the weight of approximately $200 \mathrm{~g}$, they were moved to Makrolon cages measuring $60 \times 38 \times 19 \mathrm{~cm}$. Rats were not handled except for handling associated with regular cage cleaning. The weight of subjects was $400-450 \mathrm{~g}$ at the beginning of the test period. Food and water were available ad libitum throughout, while temperature and relative humidity were kept at $22 \pm 2{ }^{\circ} \mathrm{C}$ and $60 \pm 10 \%$, respectively. Rats were maintained in a light cycle of 12:12 hours with lights off at $0800 \mathrm{~h}$.

Litters were not disturbed before weaning, i.e. dams were allowed to raise pups under normal conditions. Litter sizes were $6-10 ; 40-60 \%$ of the pups were males. The number of litters used was 8 and 9 in Experiments 1 and 2, respectively. Only males were studied. Rats belonging to the various litters were randomly assigned to social and isolation rearing; the latter were also randomly assigned to resocialization. Social groups consisted of males that came from different litters, whereas isolated rats were taken from all litters. Consequently, all litters were represented in all groups.

Intruders used in resident-intruder tests came from the same source and weighed approximately $300 \mathrm{~g}$. These rats were housed in groups of 4-6 and otherwise maintained under similar conditions. Each intruder was used twice: before and after the resocialization period of 
the experimental animals. For the second test, intruders were randomized again; therefore none of the residents met the same intruder twice.

The experiments were carried out in accordance with the European Communities Council Directive of 24 November 1986 (86/609/EEC) and were reviewed and approved by the Animal Welfare Committee of the Institute of Experimental Medicine.

\section{Experimental procedures}

In Experiment 1, male rat pups were weaned at the age of 21 days, and were maintained for 7 weeks either in social isolation ("isolated", $\mathrm{N}=16$ ) or in groups of four ("social", $\mathrm{N}=11$, because one rat fell out from the experiment).

On the 11th postnatal week, i.e. in adulthood, all subjects were isolated in individual Plexiglas cages measuring $22 \times 38 \times 28 \mathrm{~cm}$. This step was necessary as the resident-intruder test requires a short-term social isolation for the establishment of territorial behavior. On the third day of this isolation period, a smaller intruder was placed into the subject's home cage for $20 \mathrm{~min}$ (resident-intruder test). The test was carried out in the early phase of the dark period under dim red illumination provided by two $40 \mathrm{~W}$ red bulbs placed on the ceiling of the experimental room.

Two days after the resident-intruder test, i.e. on the $11^{\text {th }}$ postnatal week, socially reared rats were regrouped in groups of four animals. In each group of four, at least two rats were unfamiliar to each other. Previously isolated animals were either resocialized, i.e. regrouped in groups of four isolated rats ("iso-resoc", $\mathrm{N}=8$ ), or were housed individually in a new cage ("isoiso", $\mathrm{N}=8$ ). These two groups were matched based on their aggressive behavior shown in the 
resident-intruder test before resocialization. In each cage, rats were individually marked with permanent hair dye.

We showed earlier that aggressive behavior is frequent immediately after the formation of a new group of unfamiliar rats, but it decreases within four days and remains stable thereafter (Mikics, Barsy, \& Haller, 2007). Therefore, in the present study, aggressive interactions were analyzed in detail immediately after resocialization, and five days later ("group aggression"). One hour-long video recordings were taken at the beginning of the active (dark) phase of the day (between 900-1100 h), and behavior was analyzed as described below.

During the three weeks of resocialization, huddling behavior during sleep was assessed every day, during the early phase of the light (inactive) period, around 2100-2200 h. Photographs were taken by three webcameras from three different angles, and direct physical contacts were analyzed on these photographs. To control for accidental variability of the data, two days were analyzed together, i.e. the $1^{\text {st }}$ and $2^{\text {nd }}$ days, the $3^{\text {rd }}$ and $4^{\text {th }}$ days, etc. Huddling behavior was characterized by sleeping in direct physical contact with at least one cage mate. If no such contacts were established, rats were considered "separated".

After three weeks of resocialization, all animals were exposed again to the residentintruder test, as described above.

To assess whether social skills of cage mates affect deficient huddling behavior of isolated rats, a second experiment (Experiment 2) was run. In this experiment, rats submitted to postweaning social isolation (similarly to Experiment 1) were either resocialized in groups of four isolated rats (similar to iso-resoc in Experiment $1, \mathrm{~N}=8$ ), or in groups of one isolated and three "normal", socially reared rats $(\mathrm{N}=7)$. A socially reared group was also added as a control group 
(similar to social in Experiment $1 ; \mathrm{N}=8$ ). Huddling behavior was assessed on the $1^{\text {st }}-2^{\text {nd }}$ and the $8^{\text {th }}-9^{\text {th }}$ day of group housing, similarly to Experiment 1.

\section{Behavioral analysis}

The aggressive behavior of subjects was studied before and after the resocialization period by means of the resident-intruder paradigm. Behavior was video-recorded and biting attacks were later analyzed in detail by an experimenter blind to treatment conditions. We recorded the number of attacks, their targets on the body of opponents and their behavioral context as these were the variables that showed marked alterations after social isolation (Tóth, et al., 2008; Toth, et al., 2011; Toth, et al., 2012). Attack episodes were analyzed at low speed, frame-by-frame when necessary. An attack was considered a vulnerable area-attack if it targeted the head (areas anterior to the ears), throat (the ventral area below the ears), belly (ventral areas between legs) or the paws of the opponent. The back and the flanks (posterior to the ears and dorsal to the legs) were considered non-vulnerable targets. An attack was considered signaled if it was directly preceded by an offensive threat (aggressive grooming, mounting, lateral threat, chasing, wrestling, offensive upright, dominant posture), and it was considered non-signaled if it was not performed in the context of an offensive behavior. We also differentiated soft and hard bites. An attack was identified as "hard bite" when it involved kicking (clinch fights) or induced a strong startle response in the intruder (large jumps or immediate submission). "Soft bites" were not associated with kicking and induced no response or mild quivering only. Similar discriminations of attack bites were employed earlier (Halasz et al., 2008; Haller, van de Schraaf, \& Kruk, 2001; Tóth, et al., 2008). 
Aggressive behavior was also assessed on the first and the fifth days of the resocialization period ("group aggression"). One hour-long video-recordings were analyzed daily. The frequency of offensive threats and dominant postures, as well as that of defensive behavior (defensive upright, flight) and submissive postures (lying on back while kept down by the opponent) were recorded for each individually marked animal. During analysis, we observed a behavior called later "unprovoked defense". This behavior was elicited by non-threatening events, e.g. a cage mate exploring nearby or sniffing at the respective animal, or sometimes even by stimuli coming from outside the cage (sounds from other cages), whereas normal, "provoked defense" was a reaction to an offensive behavior of an opponent. Therefore defensive behavior was divided into provoked and unprovoked defense. Attack bite counts and vulnerable areaattacks were also counted. As attack counts were relatively low during group aggression, only total attack counts were shown in this case, i.e. subtypes of attacks were not differentiated. As vulnerable area-attacks were practically absent in animals housed in groups, they will not be discussed further.

\section{Statistical analyses}

Data obtained in the resident-intruder test were analyzed by Kruskal-Wallis ANOVA (K-W) and the Mann-Whitney (M-W) post-hoc tests because the distribution of behavioral data was not normal. The ratio of rats showing huddling behavior during the inactive phase was compared by the Chi-square test. The frequency of aggressive acts performed during group-housing required two-factor analysis. Therefore, data were square-root transformed to fulfill ANOVA assumptions and were evaluated by repeated measures ANOVA (repeated measures Factor 1 was time whereas Factor 2 was the rearing 
condition), followed by Newman-Keuls post-hoc tests where the interaction was significant.

Data on aggressive behavior were expressed as means \pm SEM throughout. Significance level was set at $\mathbf{p}<0.05$.

\section{Results}

As expected, post-weaning social isolation led to abnormal attack patterns in the residentintruder test, i.e. increased share of vulnerable area-attacks (Table 1; $\mathrm{M}-\mathrm{W} \mathrm{U}=38, \mathrm{p}=0.01$ ). Quantitative measures of aggressiveness (soft, hard and total attack counts), and the share of nonsignaled attacks (expressed as the percentage of total attack counts) showed no significant changes. Isolation-reared groups that were later resocialized (iso-resoc) or left isolated (iso-iso) behaved similarly in this first resident-intruder test $(\mathrm{K}-\mathrm{W} \mathrm{H}(2,27)=6.85, \mathrm{p}=0.033$; post-hoc: social vs. iso-iso $\mathrm{M}-\mathrm{W} U=21 . \mathrm{p}=0.039$; social vs. iso-resoc $\mathrm{M}-\mathrm{W} U=17 . \mathrm{p}=0.018$; iso-iso vs. iso-resoc: n.s.; other variables: K-W tests n.s.).

Aggressive behavior during resocialization showed interesting group differences (Fig. 1). Offensive behavior depended on the interaction between factors $\left(F_{\text {interaction }}(1,17)=8.61, p=\right.$ 0.009). Post-hoc analyses revealed that socially reared animals showed a high level of offense on the first day, which was absent in isolated animals $(\mathrm{p}<0.001)$. On the fifth day, both groups showed a low level of offense (n.s.). Dominant postures showed a similar pattern, the interaction between factors was significant $\left(\mathrm{F}_{\text {interaction }}(1,17)=5.28, \mathrm{p}=0.034\right)$. Post-hoc analysis indicated that socially reared but not isolation-reared rats showed this behavior frequently on the first day $(p=0.003)$, while both group showed this behavior rarely on the fifth day (n.s.). Total attack counts were similar in the two groups on both days. On the first day, a low number of attacks were shown (social vs. zero: $\mathrm{t}(10)=2.24, \mathrm{p}=0.048$; iso-resoc vs. zero: $\mathrm{t}(7)=3.38, \mathrm{p}=0.01$; 
social vs. iso-resoc: n.s.), while on the fifth day, we did not observe attack bites in either group. Submissive posture was rare in both groups, however it showed a marginally significant effect of rearing condition with somewhat lower frequencies in the isolated group $\left(\mathrm{F}_{\text {rearing }}(1,17)=3.87 ; \mathrm{p}\right.$ $=0.066$ ). Provoked defense was low in both groups on both days, and did not show any statistical difference. Unprovoked defense occurred rarely in socially reared rats on the first day, and was practically absent on the fifth day. Isolated rats readily showed this behavior on both days $\left(\mathrm{F}_{\text {rearing }}(1,17)=31.5 ; \mathrm{p}<0.001\right)$.

Isolation-reared rats showed considerably decreased huddling during sleep as compared to the socially reared group (Fig. 2). This difference was statistically significant on days 1-2 $\left(\mathrm{Chi}^{2}(1)=7.90, \mathrm{p}=0.005\right)$ and days $5-6\left(\mathrm{Chi}^{2}(1)=5.83, \mathrm{p}=0.016\right)$, while in between it was apparent but not significant. This difference was undetectable one week after resocialization. On the last two days of resocialization a reversed difference was also observed (days 19-20: $\mathrm{Chi}^{2}(1)$ $=4.94,0.026)$. When weekly averages were compared, the robust decrease of social contacts was shown by isolated rats during the first week of resocialization $\left(\mathrm{Chi}^{2}(1)=5.51, \mathrm{p}=0.019 ;\right.$ Fig.2), but not on the second and third week, when they behaved similarly to socially reared rats (n.s. for both weeks).

In Experiment 2, the huddling behavior of rats submitted to post-weaning social isolation did not depend on the social background of cage mates (Fig. 2, right-hand panel). On the $1^{\text {st }}-2^{\text {nd }}$ days of resocialization isolated rats rehoused with either other isolated or with normal socially housed animals showed a significantly lower rate of huddling compared to socially housed controls $\left(\mathrm{Chi}^{2}(1)=7.27, \mathrm{p}=0.007 ; \mathrm{Chi}^{2}(1)=9.24, \mathrm{p}=0.002\right.$, respectively). The two groups of resocialized isolation-reared rats showed similar huddling (n.s.). On the $7^{\text {th }}-8^{\text {th }}$ day, all three groups showed similar huddling (n.s.). 


\section{Resocialization slightly decreased attack counts in resocialized rats resulting in an} intermediate level between the socially reared and non-resocialized isolation-reared rats in the second resident-intruder test of Experiment 1. This tendency was present in soft bites (K$\mathrm{WH}(2,27)=9.64 ; \mathrm{p}=0.008$; post-hoc: social vs. iso-iso $\mathrm{M}-\mathrm{W} \mathrm{U}=12.5 . \mathrm{p}<0.003$; social vs. iso-resoc n.s.; iso-iso vs. iso-resoc n.s. ) and total attack counts $(\mathrm{K}-\mathrm{W} \mathrm{H}(2,27)=6.98, \mathrm{p}=0.030$; post-hoc: social vs. iso-iso $\mathrm{M}-\mathrm{W} U=14.5$. $\mathrm{p}=0.014$; social vs. iso-resoc n.s.; iso-iso vs. isoresoc n.s.), but not in hard bites (n.s.). However, abnormal features of resident-intruder aggression were not abolished by resocialization. The percentage of vulnerable area-attacks remained increased in both the resocialized rats and those that remained isolated throughout (Fig. $3, \mathrm{~K}-\mathrm{W} \mathrm{H}(2,27)=12.30, \mathrm{p}=0.002$; post-hoc: social vs. iso-iso $\mathrm{M}-\mathrm{W} \mathrm{U}=6 . \mathrm{p}<0.001$; social vs. iso-resoc $\mathrm{M}-\mathrm{W} \mathrm{U}=18.5 . \mathrm{p}=0.012$; iso-iso vs. iso-resoc n.s.). The percentage of nonsignaled attacks was also similar in the two isolated groups, and significantly higher than that of the social group $(\mathrm{K}-\mathrm{W} \mathrm{H}(2,27)=9.07, \mathrm{p}=0.011$; post-hoc: social vs. iso-iso $\mathrm{M}-\mathrm{W} U=15 . \mathrm{p}=0.009$; social vs. iso-resoc $\mathrm{M}-\mathrm{W} \mathrm{U}=16 . \mathrm{p}=0.011$; iso-iso vs. iso-resoc n.s.).

\section{Discussion}

Our findings show that post-weaning social isolation induced an inadequate social behavior in a newly formed social group in adult rats, as isolated rats hardly showed offensive and dominant behavior, while they delivered attacks in a manner comparable to controls. Intriguingly, such rats reacted with defensive postures to non-threatening behaviors of social partners. In addition, isolated rats showed decreased sleep-related huddling during the first week of social housing. After the first week, huddling behavior was normalized. Social housing, however, was unable to eliminate post-weaning social isolation-induced abnormal attack patterns 
in the resident-intruder test, as resocialized isolates still showed an increased share of vulnerable area-attacks and non-signaled attacks. In quantitative terms, aggressive behavior of resocialized rats showed an intermediate level between socially reared and non-resocialized isolation-reared rats.

Here we confirmed our earlier findings by showing that post-weaning social isolation of laboratory rats leads to qualitative changes in aggression, e.g. an increased share of attacks that are aimed at vulnerable body parts of intruders in the resident-intruder test, in a situation in which the experimental animal is in a winner position (Tóth, et al., 2008; Toth, et al., 2011; Toth, et al., 2012).

When placed in a new (potentially threatening) social group, "normal" rats show frequent aggressive behaviors to build up a hierarchy, but aggression decreases rapidly afterwards (Mikics, et al., 2007). This pattern was reproduced by control animals of the present experiment. However, when placed in a group of same-sized conspecifics, isolated rats showed decreased offensive and dominant behaviors, while they were defensive even in nonaggressive situations (e.g. a cage mate exploring nearby), and delivered a normal amount of attack bites, indicating the ambiguous nature of their aggressive behavior. This is in line with the pattern observed earlier in the resident-intruder test, where the attacks of rats reared in isolation were associated with low signaling by offensive threats and increased defensiveness (Tóth, et al., 2008; Toth, et al., 2011; Toth, et al., 2012). Interestingly, decreased offense in a social group was also shown in isolationreared rhesus monkeys and chimpanzees (Harlow, et al., 1965; Reimers, Schwarzenberger, \& Preuschoft, 2007), and the generalized fearful/defensive behavior (unprovoked defense) is reminiscent of that observed as well in socially deprived rhesus monkeys (Harlow, et al., 1965; Kempes, Gulickx, van Daalen, Louwerse, \& Sterck, 2008). 
Isolation-reared rats also showed a decrease in huddling behavior during sleep. The predilection of rats towards huddling was clearly shown by our control rats, who huddled already during the first inactive period of the first cohabitation day, despite the fact that they were unfamiliar to each other and were engaged in hierarchy fights a few hours earlier (during the active period). In contrast, rats submitted to the post-weaning social isolation paradigm usually slept in distant corners of the cage, apart from social partners, despite the fact that they were considerably less involved in the establishment of hierarchy. This behavioral deficit markedly improved after approximately one week. Social withdrawal was also shown in isolated rhesus monkeys and chimpanzees (Harlow, et al., 1965; Harlow \& Suomi, 1971; Kalcher, Franz, Crailsheim, \& Preuschoft, 2008), and post-weaning social isolation of rats was also shown to induce decreased social interaction in the social interaction test (Möller, Du Preez, Emsley, \& Harvey, 2011). Similarly to our rats, rhesus monkeys and chimpanzees also showed improvements of social withdrawal after resocialization (Harlow \& Suomi, 1971; KalcherSommersguter, Preuschoft, Crailsheim, \& Franz, 2011). Importantly, decreased huddling and the improvement of this deficit showed similar patterns irrespective to rearing conditions of cage mates (social or isolated). Similar findings were reported in rats (Hol, Van den Berg, Van Ree, \& Spruijt, 1999), but not in rhesus monkeys (Harlow, et al., 1965; Harlow \& Suomi, 1971).

Post-weaning social isolation-induced abnormal attack patterns in the resident-intruder test persisted after the 3-week long resocialization in adulthood, showing the robust effects of isolation-rearing on aggressive behavior. Resocialized rats still aimed a considerable share of their bite attacks at vulnerable body parts of the opponents, and still delivered a considerable share of their bites without social signaling, similarly to those isolation-reared rats that were left isolated throughout. Quantitative measures of aggression (attack counts) showed a mild 
improvement, which is in line with literature data showing that resocialization can normalize quantitative measures of aggression in the social interaction test (Meng, Li, Han, Shao, \& Wang, 2010). In summary, these findings indicate that different symptoms induced by social isolation show different sensitivities to resocialization: while social deficits shown during social housing are relatively rapidly ameliorated, abnormal features of aggression are resilient to the same treatment. One can hypothesize that the effectiveness of resocialization would have been higher if isolated rats were resocialized with socially reared ones i.e. if social partners were socially experienced. However, it was shown that socially reared animals were more aggressive against isolation-reared conspecifics than against socially reared ones (Harlow, et al., 1965; Von Frijtag, et al., 2002). These findings were indirectly supported by our group aggression data, where the offense/defense balance was shifted to the right in isolated rats. Based on this information, one can assume that isolation-reared rats would become low-ranking in social groups. To avoid confounds deriving from rank order differences, we decided to regroup socially reared and socially deprived rats separately. Secondly, the instatement of prosocial behavior during sleep (i.e. huddling) did not depend on the social background of cage mates (Fig. 2, right-hand panel). Thus, resocialization did have a prosocial effect when all cage mates underwent post-weaning social isolation.

Interestingly, similar findings were reported in humans. Maltreatment during childhood is a risk factor for violent behavior in adolescence and adulthood (Chapple, Tyler, \& Bersani, 2005; Maxfield \& Widom, 1996; McCord, 1983). Early maltreatment is also a strong predictor of social phobia (Bruce, Heimberg, Blanco, Schneier, \& Liebowitz, 2012; Lochner et al., 2010), one major symptom of which is social withdrawal (American Psychiatric Association, 2000). Psychotherapy for social phobia is reasonably successful in these conditions (Canton, et al., 
2012; Willutzki, et al., 2012), while psychotherapy for violence produces more modest results later in life (Currie \& Startup, 2012; B. Weiss, et al., 2005). In line with these human findings, post-weaning social isolation in rats resulted in marked social deficits in social contexts, but these deficits were relatively rapidly abolished by group living. In contrast, post-weaning social isolation-induced abnormal manifestations of aggressiveness were resilient to resocialization, suggesting that different symptoms induced by social isolation (or social neglect) show different sensitivities to the same treatment.

\section{Notes}

This work was supported by Hungarian National Science and Research Fund (OTKA) grants no. 76283 and 82069 . The authors declare no conflict of interest. 


\section{References}

Acarturk, C., Smit, F., de Graaf, R., van Straten, A., ten Have, M., \& Cuijpers, P. (2009). Incidence of social phobia and identification of its risk indicators: a model for prevention. Acta Psychiatr Scand, 119(1), 62-70. doi: 10.1111/j.1600-0447.2008.01275.x

Alberts, J. R. (2007). Huddling by rat pups: ontogeny of individual and group behavior. Dev Psychobiol, 49(1), 22-32. doi: 10.1002/dev.20190

American Psychiatric Association. (2000). Diagnostic and Statistical Manual of Mental Disorders. 4th ed. Text-Revision. Washingdon DC: American Psychiatric Press.

Batchelder, P., Kinney, R. O., Demlow, L., \& Lynch, C. B. (1983). Effects of temperature and social interactions on huddling behavior in Mus musculus. Physiol Behav, 31(1), 97-102. doi: 0031-9384(83)90102-6

Bruce, L. C., Heimberg, R. G., Blanco, C., Schneier, F. R., \& Liebowitz, M. R. (2012). Childhood maltreatment and social anxiety disorder: implications for symptom severity and response to pharmacotherapy. Depress Anxiety, 29(2), 131-138. doi: 10.1002/da.20909

Canton, J., Scott, K. M., \& Glue, P. (2012). Optimal treatment of social phobia: systematic review and meta-analysis. Neuropsychiatr Dis Treat, 8, 203-215. doi: 10.2147/NDT.S23317

Chapple, C. L., Tyler, K. A., \& Bersani, B. E. (2005). Child neglect and adolescent violence: examining the effects of self-control and peer rejection. Violence Vict, 20(1), 39-53.

Currie, M., \& Startup, M. (2012). Doing Anger Differently: Two controlled trials of percussion group psychotherapy for adolescent reactive aggression. J Adolesc, 35(4), 843-853. doi: 10.1016/j.adolescence.2011.12.003

Fone, K. C., \& Porkess, M. V. (2008). Behavioural and neurochemical effects of post-weaning social isolation in rodents-relevance to developmental neuropsychiatric disorders. Neurosci Biobehav Rev, 32(6), 1087-1102. doi: 10.1016/j.neubiorev.2008.03.003

Gentsch, C., Lichtsteiner, M., \& Feer, H. (1981). Locomotor activity, defecation score and corticosterone levels during an openfield exposure: a comparison among individually and group-housed rats, and genetically selected rat lines. Physiol Behav, 27(1), 183-186. doi: 0031-9384(81)90320-6

Goedhard, L. E., Stolker, J. J., Heerdink, E. R., Nijman, H. L., Olivier, B., \& Egberts, T. C. (2006). Pharmacotherapy for the treatment of aggressive behavior in general adult psychiatry: A systematic review. J Clin Psychiatry, 67(7), 1013-1024. 
Gunnar, M. R., Morison, S. J., Chisholm, K., \& Schuder, M. (2001). Salivary cortisol levels in children adopted from romanian orphanages. Dev Psychopathol, 13(3), 611-628.

Halasz, J., Toth, M., Mikics, E., Hrabovszky, E., Barsy, B., Barsvari, B., \& Haller, J. (2008). The effect of neurokinin1 receptor blockade on territorial aggression and in a model of violent aggression. Biol Psychiatry, 63(3), 271-278. doi: 10.1016/j.biopsych.2007.04.022

Haller, J., van de Schraaf, J., \& Kruk, M. R. (2001). Deviant forms of aggression in glucocorticoid hyporeactive rats: a model for 'pathological' aggression? $J$ Neuroendocrinol, 13(1), 102-107. doi: jne600

Harlow, H. F., Dodsworth, R. O., \& Harlow, M. K. (1965). Total social isolation in monkeys. Proc Natl Acad Sci U S A, 54(1), 90-97.

Harlow, H. F., \& Suomi, S. J. (1971). Social recovery by isolation-reared monkeys. Proc Natl Acad Sci U S A, 68(7), 1534-1538.

Hildyard, K. L., \& Wolfe, D. A. (2002). Child neglect: developmental issues and outcomes. Child Abuse Negl, 26(6-7), 679-695.

Hol, T., Van den Berg, C. L., Van Ree, J. M., \& Spruijt, B. M. (1999). Isolation during the play period in infancy decreases adult social interactions in rats. Behav Brain Res, 100(1-2), 91-97. doi: S0166-4328(98)00116-8

Johnson, J. G., Cohen, P., Brown, J., Smailes, E. M., \& Bernstein, D. P. (1999). Childhood maltreatment increases risk for personality disorders during early adulthood. Arch Gen Psychiatry, 56(7), 600-606.

Johnson, J. G., Smailes, E. M., Cohen, P., Brown, J., \& Bernstein, D. P. (2000). Associations between four types of childhood neglect and personality disorder symptoms during adolescence and early adulthood: findings of a community-based longitudinal study. $J$ Pers Disord, 14(2), 171-187.

Kalcher-Sommersguter, E., Preuschoft, S., Crailsheim, K., \& Franz, C. (2011). Social competence of adult chimpanzees (Pan troglodytes) with severe deprivation history: I. An individual approach. Dev Psychol, 47(1), 77-90. doi: 10.1037/a0020783

Kalcher, E., Franz, C., Crailsheim, K., \& Preuschoft, S. (2008). Differential onset of infantile deprivation produces distinctive long-term effects in adult ex-laboratory chimpanzees (Pan troglodytes). Dev Psychobiol, 50(8), 777-788. doi: 10.1002/dev.20330

Kempes, M. M., Gulickx, M. M., van Daalen, H. J., Louwerse, A. L., \& Sterck, E. H. (2008). Social competence is reduced in socially deprived rhesus monkeys (Macaca mulatta). $J$ Comp Psychol, 122(1), 62-67. doi: 10.1037/0735-7036.122.1.62 
Krischer, M. K., \& Sevecke, K. (2008). Early traumatization and psychopathy in female and male juvenile offenders. Int J Law Psychiatry, 31(3), 253-262. doi: 10.1016/j.ijlp.2008.04.008

Lochner, C., Seedat, S., Allgulander, C., Kidd, M., Stein, D., \& Gerdner, A. (2010). Childhood trauma in adults with social anxiety disorder and panic disorder: a cross-national study. Afr J Psychiatry (Johannesbg), 13(5), 376-381.

Maxfield, M. G., \& Widom, C. S. (1996). The cycle of violence. Revisited 6 years later. Arch Pediatr Adolesc Med, 150(4), 390-395.

McCloskey, M. S., Noblett, K. L., Deffenbacher, J. L., Gollan, J. K., \& Coccaro, E. F. (2008). Cognitive-behavioral therapy for intermittent explosive disorder: a pilot randomized clinical trial. J Consult Clin Psychol, 76(5), 876-886. doi: 10.1037/0022-006X.76.5.876

McCord, J. (1983). A forty year perspective on effects of child abuse and neglect. Child Abuse Negl, 7(3), 265-270. doi: 0145-2134(83)90003-0

Meng, Q., Li, N., Han, X., Shao, F., \& Wang, W. (2010). Peri-adolescence isolation rearing alters social behavior and nociception in rats. Neurosci Lett, 480(1), 25-29. doi: 10.1016/j.neulet.2010.05.067

Mikics, E., Barsy, B., \& Haller, J. (2007). The effect glucocorticoids on aggressiveness in established colonies of rats. Psychoneuroendocrinology, 32(2), 160-170. doi: 10.1016/j.psyneuen.2006.12.002

Möller, M., Du Preez, J. L., Emsley, R., \& Harvey, B. H. (2011). Isolation rearing-induced deficits in sensorimotor gating and social interaction in rats are related to cortico-striatal oxidative stress, and reversed by sub-chronic clozapine administration. Eur Neuropsychopharmacol, 21(6), 471-483. doi: 10.1016/j.euroneuro.2010.09.006

Potegal, M., \& Einon, D. (1989). Aggressive behaviors in adult rats deprived of playfighting experience as juveniles. Dev Psychobiol, 22(2), 159-172. doi: 10.1002/dev.420220206

Queiroz, E. A., Lombardi, A. B., Furtado, C. R., Peixoto, C. C., Soares, T. A., Fabre, Z. L., .. . Lippi, J. R. (1991). Biochemical correlate of depression in children. Arq Neuropsiquiatr, 49(4), 418-425.

Reimers, M., Schwarzenberger, F., \& Preuschoft, S. (2007). Rehabilitation of research chimpanzees: stress and coping after long-term isolation. Horm Behav, 51(3), 428-435. doi: 10.1016/j.yhbeh.2006.12.011

Rivera, B., \& Widom, C. S. (1990). Childhood victimization and violent offending. Violence Vict, 5(1), 19-35. 
Sánchez, M. M., Aguado, F., Sánchez-Toscano, F., \& Saphier, D. (1998). Neuroendocrine and immunocytochemical demonstrations of decreased hypothalamo-pituitary-adrenal axis responsiveness to restraint stress after long-term social isolation. Endocrinology, 139(2), $579-587$.

Schrijver, N. C., Bahr, N. I., Weiss, I. C., \& Würbel, H. (2002). Dissociable effects of isolation rearing and environmental enrichment on exploration, spatial learning and HPA activity in adult rats. Pharmacol Biochem Behav, 73(1), 209-224. doi: S0091305702007906

Shaffer, A., Yates, T. M., \& Egeland, B. R. (2009). The relation of emotional maltreatment to early adolescent competence: developmental processes in a prospective study. Child Abuse Negl, 33(1), 36-44. doi: 10.1016/j.chiabu.2008.12.005

Spinhoven, P., Elzinga, B. M., Hovens, J. G., Roelofs, K., Zitman, F. G., van Oppen, P., \& Penninx, B. W. (2010). The specificity of childhood adversities and negative life events across the life span to anxiety and depressive disorders. $J$ Affect Disord, 126(1-2), 103112. doi: $10.1016 /$ j.jad.2010.02.132

Takahashi, H. (1997). Huddling relationships in night sleeping groups among wild Japanese macaques in Kinkazan Island during winter. Primates, 38(1), 57-68. doi: $10.1007 / \mathrm{bf02385922}$

Tóth, M., Halász, J., Mikics, E., Barsy, B., \& Haller, J. (2008). Early social deprivation induces disturbed social communication and violent aggression in adulthood. Behav Neurosci, 122(4), 849-854. doi: 10.1037/0735-7044.122.4.849

Toth, M., Mikics, E., Tulogdi, A., Aliczki, M., \& Haller, J. (2011). Post-weaning social isolation induces abnormal forms of aggression in conjunction with increased glucocorticoid and autonomic stress responses. Horm Behav, 60(1), 28-36. doi: 10.1016/j.yhbeh.2011.02.003

Toth, M., Tulogdi, A., Biro, L., Soros, P., Mikics, E., \& Haller, J. (2012). The neural background of hyper-emotional aggression induced by post-weaning social isolation. Behav Brain Res, 233(1), 120-129. doi: 10.1016/j.bbr.2012.04.025

Turgay, A. (2004). Aggression and disruptive behavior disorders in children and adolescents. Expert Rev Neurother, 4(4), 623-632. doi: 10.1586/14737175.4.4.623

van den Berg, C. L., Hol, T., Van Ree, J. M., Spruijt, B. M., Everts, H., \& Koolhaas, J. M. (1999). Play is indispensable for an adequate development of coping with social challenges in the rat. Dev Psychobiol, 34(2), 129-138. doi: 10.1002/(SICI)10982302(199903)34:2<129::AID-DEV6>3.0.CO;2-L

Veenema, A. H. (2009). Early life stress, the development of aggression and neuroendocrine and neurobiological correlates: what can we learn from animal models? Front Neuroendocrinol, 30(4), 497-518. doi: 10.1016/j.yfrne.2009.03.003 
Von Frijtag, J. C., Schot, M., van den Bos, R., \& Spruijt, B. M. (2002). Individual housing during the play period results in changed responses to and consequences of a psychosocial stress situation in rats. Dev Psychobiol, 41(1), 58-69. doi: 10.1002/dev.10057

Weiss, B., Caron, A., Ball, S., Tapp, J., Johnson, M., \& Weisz, J. R. (2005). Iatrogenic effects of group treatment for antisocial youths. J Consult Clin Psychol, 73(6), 1036-1044. doi: 10.1037/0022-006X.73.6.1036

Weiss, I. C., Pryce, C. R., Jongen-Rêlo, A. L., Nanz-Bahr, N. I., \& Feldon, J. (2004). Effect of social isolation on stress-related behavioural and neuroendocrine state in the rat. Behav Brain Res, 152(2), 279-295. doi: 10.1016/j.bbr.2003.10.015

Wiberg, G. S., \& Grice, H. C. (1963). Long-term isolation stress in rats. Science, 142(3591), 507.

Widom, C. S. (1989). The cycle of violence. Science, 244(4901), 160-166.

Widom, C. S., Czaja, S. J., \& Paris, J. (2009). A prospective investigation of borderline personality disorder in abused and neglected children followed up into adulthood. J Pers Disord, 23(5), 433-446. doi: 10.1521/pedi.2009.23.5.433

Willutzki, U., Teismann, T., \& Schulte, D. (2012). Psychotherapy for social anxiety disorder: long-term effectiveness of resource-oriented cognitive-behavioral therapy and cognitive therapy in social anxiety disorder. J Clin Psychol, 68(6), 581-591. doi: $10.1002 /$ jclp. 21842

Wongwitdecha, N., \& Marsden, C. A. (1996). Social isolation increases aggressive behaviour and alters the effects of diazepam in the rat social interaction test. Behav Brain Res, 75(12), 27-32. 
Table 1. Patterns of biting attacks in the first resident-intruder test

\begin{tabular}{lccccc}
\hline \multicolumn{1}{c}{ Groups } & $\begin{array}{c}\text { Soft bite } \\
\text { counts }\end{array}$ & $\begin{array}{c}\text { Hard bite } \\
\text { counts }\end{array}$ & $\begin{array}{c}\text { Total bite } \\
\text { counts }\end{array}$ & $\begin{array}{c}\text { Vulnerable area-attacks } \\
\text { (\% of total) }\end{array}$ & $\begin{array}{c}\text { Nonsignaled attacks } \\
\text { (\% of total) }\end{array}$ \\
\hline socially reared & $1.73 \pm 0.63$ & $2.64 \pm 1.02$ & $4.36 \pm 1.53$ & $6.25 \pm 3.46$ & $12.00 \pm 8.95$ \\
isolated (all) & $1.31 \pm 0.27$ & $3.06 \pm 0.63$ & $4.38 \pm 0.78$ & $\mathbf{3 8 . 0 4 \pm 8 . 5 2 ^ { * }}$ & $23.71 \pm 9.05$ \\
$\quad$ prospective iso-iso & $1.13 \pm 0.40$ & $3.00 \pm 1.07$ & $4.13 \pm 1.23$ & $\mathbf{4 0 . 3 8 \pm 1 3 . 3 1 ^ { * }}$ & $29.36 \pm 13.70$ \\
prospective iso-resoc & $1.50 \pm 0.38$ & $3.13 \pm 0.74$ & $4.63 \pm 1.03$ & $\mathbf{3 5 . 6 9 \pm 1 1 . 4 9 ^ { * }}$ & $18.06 \pm 12.41$ \\
\hline
\end{tabular}

Soft, hard and total bites were counted during the 20 min long resident-intruder test. Vulnerable area-attacks and nonsignaled attacks were shown as percentages of total attack bites. Iso-iso and iso-resoc are the two subgroups of post-weaning social isolation-reared rats. During the first encounter, these two groups were similar, as resocialization followed this encounter. *Significant difference from socially reared rats $(\mathrm{p}<0.05)$. 


\section{Captions}

Fig. 1. Frequencies of different aggressive behaviors in the first hour of resocialization, and five days later in Experiment 1. $\square$, Socially reared rats; $\square$, isolation-reared rats resocialized with other isolation-reared rats (iso-resoc). *Significant post-hoc difference between groups at the given time-point $(\mathrm{p}<0.05)$; ${ }^{\#}$ significant effect of rearing condition in the repeated measures ANOVA model $(\mathrm{p}<0.05) ;{ }^{+}$marginally significant effect of rearing condition in the repeated measures ANOVA model $(p=0.066)$.

Fig. 2. Decreased sleep-related huddling in isolated rats during the inactive period of the day. Percentage of rats showing huddling (rats which slept in direct physical contact with at least one cage mate) in Experiment 1 are shown. In the left-hand panel, two consecutive days were considered together (see Methods), in the middle panel, weekly averages are shown. In the righthand panel, data obtained in Experiment 2 are shown. $\square$, Socially reared rats; $\square$, isolation-reared rats resocialized with other isolation-reared rats for three weeks (iso-resoc); $\bullet$, isolation-reared rats resocialized with socially reared control rats. *Significant difference from socially reared rats $(\mathrm{p}<0.05)$.

Fig. 3. Attack bite counts in the second resident-intruder test, which followed the three weeklong resocialization period. $\square$, Socially reared rats (social); $\mathbf{\square}$, isolation-reared rats that were left isolated throughout (iso-iso); $\square$, isolation-reared rats resocialized with other isolation-reared rats for three weeks (iso-resoc). *Significant difference from socially reared rats $(p<0.05)$. 

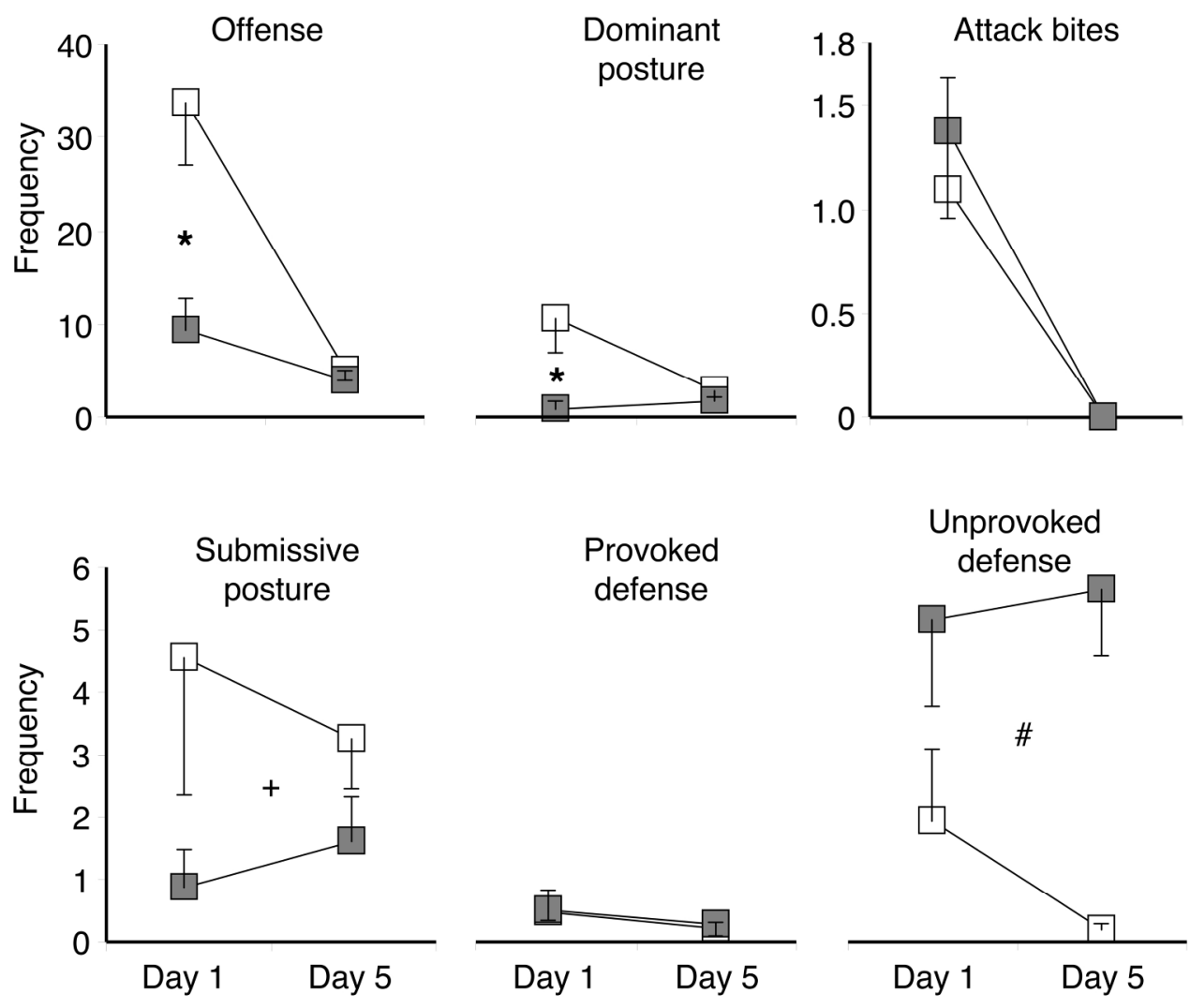

Provoked defense

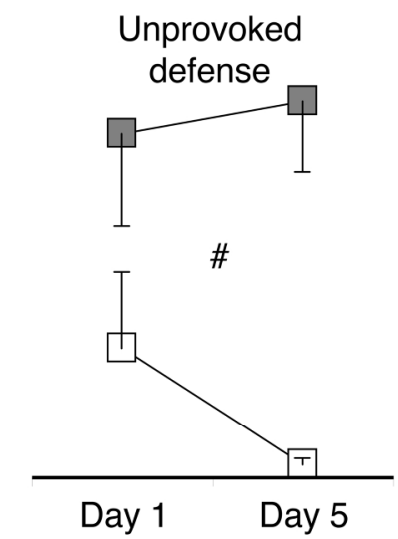

Fig. 1

$111 \times 94 \mathrm{~mm}(600 \times 600 \mathrm{DPI})$ 


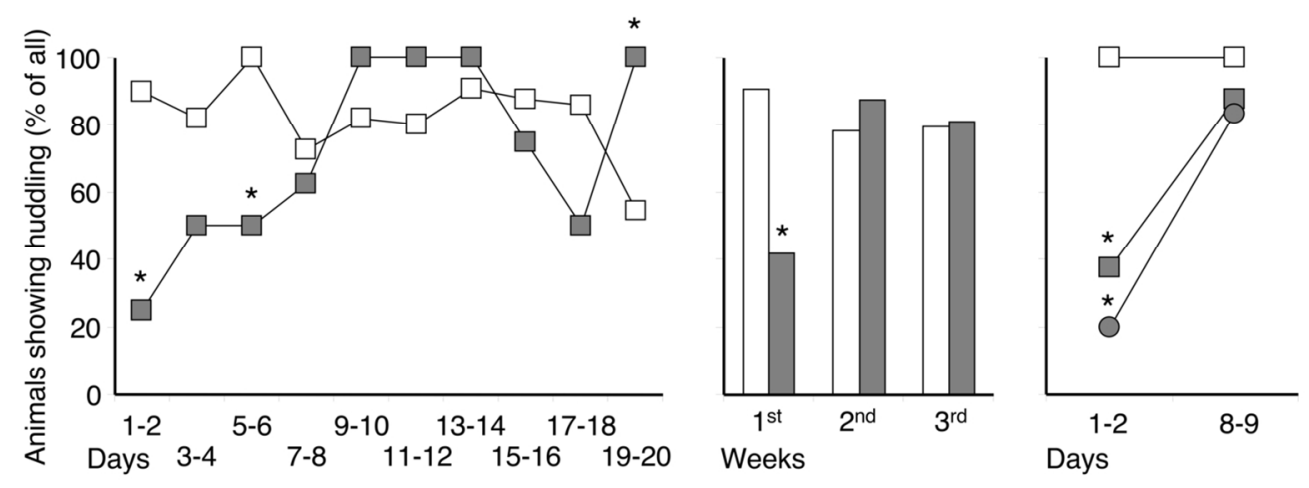

Fig. 2

$62 \times 23 \mathrm{~mm}(600 \times 600$ DPI $)$ 

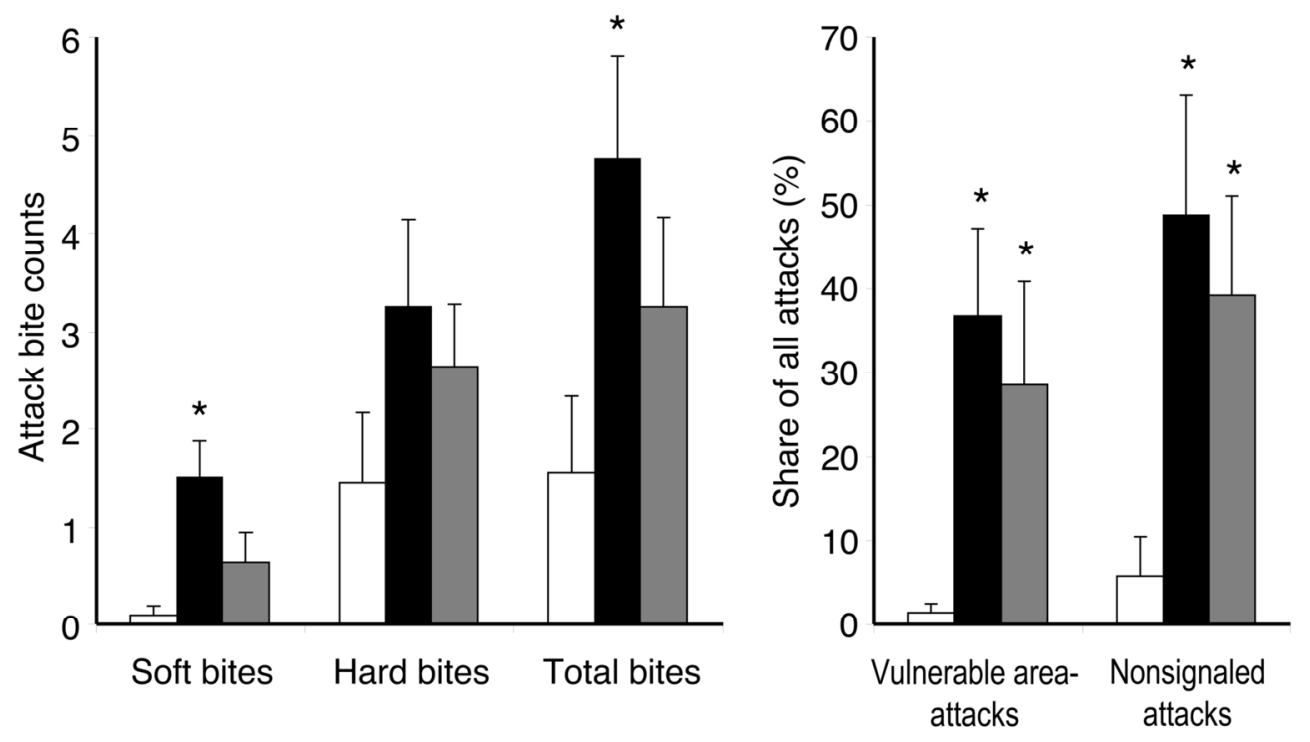

Fig. 3

$74 \times 42 \mathrm{~mm}(600 \times 600 \mathrm{DPI})$ 